\title{
Prognostic Stage 0 Breast Cancer AJCC v8
}

National Cancer Institute

\section{Source}

National Cancer Institute. Prognostic Stage O Breast Cancer AJCC v8. NCI Thesaurus.

Code C139555.

Stage 0 includes: T is, N0, M0, G1-3, HER2 Status: Any, ER Status: Any, PR Status: Any. T is:

Ductal carcinoma in situ. Lobular carcinoma in situ is a benign entity and is removed from

TNM staging in the AJCC Cancer Staging Manual, 8th Edition. NO: No regional lymph node metastasis is identified or isolated tumor cell clusters (ITCS) are identified only. G1: Low combined histologic grade (favorable); SBR score of 3-5 points. G2: Intermediate combined histologic grade (moderately favorable); SBR score: 6-7 points. G3: High combined histologic grade (unfavorable); SBR score of 8-9 points. M0: No clinical or radiographic evidence of distant metastases. Imaging studies are not required to assign the M0 category. (AJCC 8th ed.) 